\title{
Institutional Environment(s) for Online Course Development and Delivery
}

\author{
Ralph B. McNeal Jr. \\ Department of Sociology, U-1068 Storrs, CT 06269 , University of Connecticut, United States \\ *Corresponding Author: ralph.mcneal@uconn.edu
}

Copyright $@ 2015$ Horizon Research Publishing All rights reserved.

\begin{abstract}
There is a lot we know about online courses, but a lot is yet to be discovered. We know quite a bit about how to develop these courses, as well as how to deliver them. We know quite a bit about assuring the quality of these courses, and how to assess student performance. We know quite a bit about how to "incentivize" faculty to develop these courses, and about their equivalence to hybrid and traditional classroom-based courses. What we do not know, and what Sociology can contribute to the discussion, is how the institutional environment affect's individual faculty member's propensity and ability to develop and deliver online courses. This manuscript attempts to tackle these issues and discusses nine different elements that affect the development and delivery of these courses including the technological/teaching context, the political environment, faculty and administrative resistance, competing agendas, course ownership, resources, specialists and technology, and the human touch. Each of these areas is discussed in the article then linked to an individual case study at a large research University in the Northeastern United States.
\end{abstract}

Keywords Online Course Development and Delivery, Institutional Environment

\section{Introduction}

When it comes to online courses, there is a burgeoning literature on several fronts. There is an established body of literature on how to develop online courses from the administrative or institutional perspective (Knowles and Kalata, 2007 [7]; Oblinger and Hawkins, 2006 [12]; Porter, 2010 [13]), how individuals should go about developing online courses (Horton, 2000 [6]; Knowles and Kalata, 2007 [7]; Ko and Rossen, 2003 [8]; Powell, 2001 [14]), how to deliver online courses (Powell, 2001 [14]), how to assure the quality of online courses (Chao, Saj and Tessier, 2006 [2]; Koontz, Hongqin and Compora, 2006 [9]; Smith, 2008 [17]; Vai and Soculski, 2011 [20]), on the incentives and/or "coercive" measures used by administrators to convince instructors to develop and teach online courses (Berg, 2002
[1]; Oblinger and Hawkins, 2006 [12]), and on assessing the effectiveness of the online learning environment (e.g. Russell, 2001 [15]; Dutton, Dutton and Perry, 2002 [4]; Dutton and Dutton, 2005 [3]; Fjermestad, Hiltz, and Zhang, 2004 [5]; Schultz, Schultz and Round, 2008 [16]; Sussman and Lee, 2010 [18]; Urtel, 2008 [19]). What is missing is a discussion of the administrative, socio-cultural, political and institutional barriers individual faculty encounter when trying to develop and/or deliver online courses. This paper briefly explores these topics; each concept is covered theoretically, followed by a discussion of a case study to illustrate the concept(s).

The case on which much of this discussion is based corresponds to the development of an online course in 2004 at a large research university in the Northeastern United States. The university prided itself on being technologically savvy and near the forefront of the online course development process among traditional colleges and/or universities. It had an Institute for Teaching and Learning (ITL) that "provides pedagogical and technology support for faculty, graduates and undergraduate students in a variety of ways." The ITL provided support for, among other things, audio-visual technology services, media development, and instructional design and development. The institute also provided an Instructional Resource Center for faculty, graduate students and adjunct instructors. One purpose of the instructional design and development mission was to help plan, design and implement distance education courses -including online classes; at the time, the ITL had been providing support for online course development for the previous 2 years. The university had a full complement of online courses and offered some degree programs with extensive online components; two examples are the Masters of Accounting and the Bachelors of General Studies degrees. It is within this context that the examples are drawn to illustrate the key theoretical concepts.

\section{Technological / Teaching Context}

One important element that affects an instructor's desire and ability to adequately develop and deliver online courses 
is the institutional technological and teaching environment of their home institution. There are at least three factors to consider. First, to what degree does the institutional culture generally support technological advancement as a whole? Second, to what degree does the institutional culture support teaching innovation? Third, to what degree does the institutional culture focus on teaching excellence? These three factors are inter-related and are hard to separate from each other as some are dependent on others. For example, one could argue that there is a link between technological advancement as a whole and teaching innovation as innovation in today's age almost inevitably includes technological advancement of some form.

The university in question had a strong commitment to technological advancement. New, technologically advanced classroom buildings were being erected. The entire campus was wireless. The university undertook the use of i-clickers several years later and faculty were encouraged to use technology (the web / blogs / various websites) in their classrooms. The university also had a full complement of online courses; at least one online course was offered in each of the University's Schools or Colleges except for Medicine and Dental Medicine. There were funds available to develop online General Education courses. There were also funding mechanisms to convert traditional classroom pedagogy and assessment in such a manner as to be consistent with existing and emerging technological advances.

In terms of recognizing excellence in teaching, the university presented several annual awards. In addition to teaching scholarship, the university recognized teaching excellence among graduate instructors, adjuncts and faculty. The local chapter of the American Association of University Professors recognized teaching excellence among junior faculty, excellence in teaching mentorship and innovation in teaching. The alumni association recognized faculty excellence in teaching. There were also several awards for teaching excellence given out by various student organizations. Furthermore, teaching quality and excellence are essential components of the tenure and promotion processes.

In such a setting, it was easy to conceptualize and pursue online course development. It was often viewed as a technological savvy, innovative teaching technique that should be encouraged. But the story is not complete if you just look at the broad, institutional structures since there is a wide array of actors involved in how, and whether, online courses are fully developed, supported, and implemented.

\section{Political Environment}

The general political climate, especially at the administrative and faculty levels, is also crucial to understanding online course development and delivery. As with any institution, there is an organizational culture at both the executive and "worker" levels. What the executives want or foster is not necessarily what the workers want or foster as part of this culture. In short, they both have intellectual and political agendas that may be similar or dissonant with each other.

A university or college, as an institution, is no different. There are multiple organizational units and each has its own agenda or culture in which online course development takes place. This is evident in the literature regarding the incentives to offer online courses; in many cases university administrations pushed for online courses without duly considering the effectiveness of the courses (Urtel, 2008 [19]), nor the maintenance cost for the faculty developing and teaching these classes (Oblinger and Hawkins, 2006 [12]). In 2008, a taskforce was developed to address several issues (4 years after the initial wave of course development). Only at that time were development and maintenance costs first raised organizationally.

As for the supporting case study, there was strong support from the Provost and Executive Vice President for Academic Affairs (Provost), the Associate Vice-Provost and Director of the Institute for Teaching and Learning (Associate Vice-Provost), and the Dean of the College of Continuing Studies (Dean CCS). Their offices collectively provided financial support for early online course development. These administrators were also behind the expansion of the ITL. Their finances ultimately provided curriculum specialists, course development specialists, and computer programmers - among others. In this case, the general climate at the university was supportive of online courses -- at the beginning. As an enticement, faculty members were offered an initial cash stipend to support their developing online courses; the stipend was most frequently granted to cover summer time spent on course development. In the literature, cash stipends are often conceptualized as "coercive" measures used by administrators to convince instructors to develop and teach online courses (Berg, 2002 [1]; Oblinger and Hawkins, 2006 [12]). One shortcoming was the University's determination of course quality and effectiveness. While there were rubrics that were tightly followed when developing some courses, they were not consistently used across all courses. Furthermore, while the rubrics were critical component, there was no scientific evaluation or measurable elements for course effectiveness. Similarly, support for course maintenance costs were variable - a topic I will return to later.

The support by all parties was not necessarily driven by an interest in technological or pedagogical advancement per se, but sometimes often as a means to an end. While the Associate Vice-Provost had a strong interest in the pedagogical value and usefulness of online instruction, other administrators saw online courses as a way to expand enrollment without placing additional demands on physical resources or as a way to garner additional income. In fact, a taskforce that was formed to study online course development was explicitly charged to make "suggestions on prioritizing focus areas with greatest potential for return." (emphasis added) While one can contend that "greatest 
potential for return" could be conceptualized as value-added academic outcomes, it is much more likely an issue of fiscal returns.

The emphasis on online course development coincided with nearly unprecedented enrollment growth and building expansion. To make matters worse, there was concern about the growth of the university and the carrying capacity of the physical facilities. It was initially thought that eliminating current classroom buildings might first be necessary to build new classroom facilities in their place. Combined with rapid growth, this meant there was the possibility of not having any "replacement" seats available. Online courses were viewed by the Provost as one potential means to resolve the problem in a fiscally inexpensive manner.

There were unanticipated developments during the process of online course development that affected the political climate. The Provost, who was very supportive of the online movement, left for an administrative post at another university. Although the Associate Vice-Provost was strongly supportive, there was nobody "in charge of the ship" per se; a key advocate was missing. The loss of the Provost may have been one contributing factor to the small but growing resistance to online courses that was exhibited several years later.

\section{Faculty and Administrative Resistance}

As with any new innovation, online courses were not overwhelmingly supported by members of the institution themselves. There can be organizational resistance at many different levels and for any number of reasons. There can be organizational resistance by those in positions of authority driven by a number of concerns for the institution's prestige and image and/or as threats to the more 'traditional' education. There can be resistance by faculty due to a sense of jealousy or possessiveness and concern(s) about the quality of a student's education. Both of these forms of resistance became evident at the university shortly after the first wave of online courses were developed.

Approximately two to four years after the first wave of online courses were developed, a small collection of individuals emerged on campus that opposed online courses. Among other things, some administrators and faculty were skeptical about the role of online courses at the University, the ability to develop and deliver online courses, and the quality and integrity of online courses. In at least one case, an online course already developed was prohibited by department administration from being taught again until there was solid scientific evidence that the online course was at least as effective as a face-to-face class. This requirement was set in place despite the extensive evidence from the "no-significant-difference" literature where Russell (2001 [15]) has already documented their equivalence. Similarly, a second course was in a Department that changed administrative leadership and the decision was made to discontinue offering the course. This University operates under a Strong-Head model whereby the Head has a stronger influence on curriculum than would a Department Chair.

Following these issues, there was a slowdown of online course development. One interpretation is a general "chilling" effect on online course development; on the other hand, one administrator recently stated that the slowdown, in his opinion, was more closely tied to not having available "incentives." At this time, the number of online courses being developed slowly declined. Simultaneously, coupled with the recognition that the growing concerns had to be met, the Provost later formed a task force to study the issues (2008, while the initial resistance/concerns emerged in 2004). The 2008 taskforce was composed of twelve members, four of whom had developed and taught online courses. The taskforce had several charges, including among others:

- Examine the expectations and qualifications of faculty who seek to develop an online course

- Explore intellectual property policies that maximize financial benefit to all parties

- Provide a summary of views on the role of formal instructional design in online course development

- Investigate the needs and methods for new course approval and year-over-year evaluation of course quality

- Make suggestions on prioritizing focus areas with greatest potential for return

Within these charges, the taskforce was to take into consideration "...the current financial realities" and "...should carefully consider cost containment and revenue generation as critical factors in all of its conclusions and recommendations." They were further asked to explore "...the financial and reputational opportunities and risks for the university of an online education initiative." In other words, where do online courses fit financially in terms of cost to develop, maintain and deliver AND in terms of their profitability? In response to quality concerns, the taskforce was also charged with developing guidelines or methods to determine the quality of online courses; this is a standard that is not always present or applied to face-to-face classes. When one committee member questioned whether the University would simultaneously assess each "face-to-face" class and whether they would have to meet the same standard, that member was mysteriously not asked to attend later meetings of that taskforce nor to be a member of a later taskforce.

At the colleague or faculty level, some faculty asked if they could teach "your / my course", with the assumption that the online course would be available to the Department faculty as a whole. Another colleague mentioned the unfair advantage of being able to teach the course "from the South of France." Other colleagues insisted on the course only being taught a second time if it could be empirically proven to be equal to a face-to-face course. Even after this was established via a quasi-experimental study, and with the no-significant-difference literature being widely documented elsewhere, the course was not approved to be 
offered subsequently - until summer 2011 - a seven year lag. At that time, a course previously developed was "refreshed" and offered during summer school; the course has not been subsequently offered, a 3-year lag. On another note, this Department has never offered an online course during the standard academic year.

Finally, the resistance in some disciplines was sufficient enough that there was a reduction in course development. After the taskforce made their recommendations, there was a gradual increase in course development, although there was no longer any direct institutional financial support to do so. Several years later, the university "incentivized" course development - meaning faculty members were once again paid for course development.

In summary, there was some opposition to online courses composed of an odd collection of faculty and administrators (1) who had little faith in the validity of online courses, (2) who saw online courses as a way to undermine enrollment in face-to-face classes, (3) who were concerned about the online courses eroding the traditional college curriculum, and (4) who saw online courses as having an inherent advantage for the faculty who was offering the course. Nobody in opposition necessarily seemed to be concerned about the non-financial cost to develop or deliver the course. While the initial financial incentive was a summer stipend, the concerns of lost research productivity while developing the course, loss of credit toward merit for developing the courses, nor the manpower or resources on the part of the faculty member to maintain the online course were largely unaddressed. One administrator, during a recent conversation, claimed that conversations took place on a case-by-case basis. Follow-up conversations with three faculty from the first wave of development reveal these conversations never took place. There is no way to determine which side's story is accurate, although the 3-1 ratio is telling.

Some faculty suddenly found themselves in the midst of a power struggle between those in opposition of online courses and those in support. Some departments went ahead with subsequent online courses while others stopped delivering and offering online courses altogether. Furthermore, in at least one case, a course that was previously taught was discontinued because a new Department Head was opposed to the online curriculum. The active resistance, despite only limited long-term success, effectively derailed some of the short-term momentum of online course development. Key administrators contend online course development is now in full-swing, but also admit some Departments have chosen not to participate in the online course development process.

\section{Politics and Competing Agendas}

There are various political agendas that the instructor might encounter when developing and delivering online courses. This is particularly true when there are competing agendas. Some might want the online courses to succeed for fiscal purposes; some might have a vested interest in the pedagogical or technological value of online courses; some might have more practical concerns such as enrollment pressures or demands.

In this particular case, the agendas included those set forth by the Provost, the Associate Vice-Provost, the Dean of CCS, the technical support staff and the faculty members themselves. The Provost is often charged with looking out for the academic welfare of the university as a whole. In this case, the Provost provided financial support for online course development - primarily through technical support staff. The Provost saw online courses as a means to an end. These courses allowed expanded enrollment without additional demand on physical resources such as classroom seats. In theory, online courses have a near limitless enrollment capacity and need only sufficient instructional support. Virtual enrollment and expansion remained one of the Provost's key agenda items.

The Associate Vice-Provost also had an agenda. The Institute had an academic and professional interest in the online courses. The main goal, as espoused by the Associate Vice-Provost, was to assure these courses were developed following rigorous academic standards and that they were evaluated scientifically; the need for rigorous academic standards is one of the recommendations that the Taskforce ultimately made. This meant that the development process took more time than anticipated as each course went through an intensive instructional design process. The ITL also provided funding for course development via specialists and computer programmers. To date, there has still not been an empirical assessment of the courses' effectiveness.

The Dean of the CCS also had an agenda: increased summer enrollment and the accompanying revenue. One issue facing Universities in general is the loss of revenue from summer school for students taking summer courses "back home"; a large majority of students take courses at their local institution. These courses are then transferred to their home institution. This University is no different. This leads to two problems. First, as previously mentioned, there is a loss of revenue. Second, there are often matriculation concerns when summer school courses do not have a corresponding partner at the home institution.

The Dean of CCS also pushed to offer online Bachelor's degrees for the non-traditional students; while the entire degree was not online, she by and large succeeded at developing BGS online courses despite opposition by some faculty and departments. Given the unusual funding arrangement between the CCS and the rest of the University, the more students taking courses through $\mathrm{CCS}$, the more profitable the CCS became. In short, online courses were perceived as a revenue generator. As an aside, partial funding from three administrative units (Provost's office, ITL and CCS) led to some unanticipated problems with developing online courses.

Finally, there was the faculty member. The faculty member's agenda varied from one instructor to the next, but 
most were intrigued with the idea of online course delivery and instruction and had an intellectual interest in seeing that the course(s) were developed scientifically and rigorously. A few, however, held the misguided belief that the online course would somehow mean less work after the initial investment in course development. In reality, these faculty members discovered that developing and teaching online courses can lead to a heavier workload than a regular face-to-face class. One particular element that lead to a heavier workload was the high maintenance cost that the faculty incurred once original course development was completed. The faculty member's agenda is also nested within the other political agendas, which further mires their desire and ability to develop online courses.

These agendas primarily affect a faculty member's propensity to develop online courses. Political agendas set a general tone regarding online courses as a whole and individual member's propensity in specific. The goals or impetus for course development is of critical importance to many faculty members. While some may be sympathetic to organizational needs for more seats, they may feel that it undermines the quality of a student's education. Some faculty members may be sympathetic toward students' needs for summer courses and matriculation concerns; others may not.

\section{Ownership}

Ownership of online course material has drawn much attention in the past several years (Kranch, 2008 [10]; Loggie, Barron, Gulitz, Hohfield, Kromrey and Sweeny, 2007 [11]). While it seems the issue should be relatively straight-forward, it is highly controversial and should be resolved prior to any course developing taking place. Is online course material similar to scientific innovations where the university owns the patent? Is it a work-for-hire often found in the consulting world where a faculty member relinquishes the rights to the material to the university or a particular division within the university? Is it similar to a publication where the faculty member retains copyright privileges despite having used university resources to help create the product? Who has the right to retain the copyright - the university, a particular division of the university, the technological experts, or the faculty members?

In the current case, since so many different entities contributed to the development and delivery of the online course(s), it should come as no surprise that ownership, or copyright, became an issue. The Provost contended that since his office provided substantial funding that the University would own the copyright. The Associate Vice-Provost contended that they controlled the copyright, while recognizing the University's primary claim of ownership, because they provided the support staff that helped develop the curriculum and the interface for online course delivery. The Dean of CCS contended that since they provided summer funding for faculty, and some initial seminars and workshops on online courses, that they owned the copyright due to a work-for-hire arrangement.

Some technical support staff contended that they owned the copyright, or at least had a significant say in the product's future, since it was their unique intellectual property. Lacking a clear vision of online course development, and paying little attention to branding in the early stages, each course was "unique." Everything from the access portal, user interface, presentation of materials, and assessment was unique. It truly was a situation where each support staff and technical specialist created and developed their own courses; it was thus easy to see why they claimed some ownership in the project. The University now has a relatively consistent delivery portal / interface, although individual faculty are allowed to deviate from this format at their choosing.

Finally, some faculty members claimed ownership of the copyright since ultimately it was their substantive intellectual property including lesson plans, presentation material, and assessment methods and materials. This led to tension between the parties and a work slow-down for a short period of time in some courses until the copyright issue could be resolved. The ultimate decision was that the copyright issue would remain unresolved and would be addressed if and when an issue arose; in the interim, the Task Force was charged with tackling the topic.

The Taskforce later recommended that the University establish guidelines and possibly contract language detailing the funding and intellectual ownership of online classes. At other universities, guidelines have already been established and online courses are owned entirely by the university and their development is treated as a work-for-hire arrangement (Loggie, et al., 2007 [11]). This is the complete opposite model of intellectual property being retained by the faculty member. Each will differentially affect course development and delivery. Clearly, ownership of the online product is something that should be explicitly addressed to foster online course development. At this University, there is now a Memorandum of Understanding between the University and the faculty union providing guidelines for course development, and more importantly course ownership and copyright

\section{Resources}

From an administrative perspective, one of the most pressing concerns is resources. If nothing else, developing, delivering and modifying online courses are resource-hungry beasts that must be fed. The range of support is quite impressive. It takes resources to propose, develop, technologically support, establish assessment protocols, transform existing assessment materials into something compatible with the online environment, provide teaching assistants, and provide technical support and resources for later revisions and modifications.

From where these resources come is important. As seen earlier, receiving resources from multiple administrative 
units is complicated. Whose agenda most closely aligns with the instructor's interests and needs? Clearly, receiving funding coincides with an expectation of outcome that is compatible with the given unit's agenda. It is best if there is a college or university-wide systematic agenda under which online course development operates.

The model that developed at this university was one where the Provost paid for developing online courses, the Associate Vice-Provost provided the technical support and the Department is expected to provide the teaching assistant support. However, this was not always the case. In a few cases, faculty members were met by opposition from their Department Heads that either refused to schedule the online course or refused to provide much needed teaching assistant support. In at least two cases, the Department Head at the time of course development was very supportive of the online course, but a newer Department Head was not and was reluctant to or refused to offer the online course.

While universities financially support developing online courses, few realize the extent of the resources necessary to maintain an online course versus a face-to-face class. For example, if the presentations are streamed, they need to be re-streamed every semester in order to incorporate items such as current events. If they are power-point presentations, they must be updated every semester to be contemporary. This requires resources such as money, equipment, and staff. If the instructor changes his textbook, the course may need to be substantially modified depending on the extent to which your class presentations were tied to that text. To address this concern, one faculty developed his courses from scratch, starting with course objectives and topical objectives independent of a textbook. However, this was no consistent across all initial classes. All of these concerns may exist for traditional, face-to-face classes, but they are more pronounced for distance learning courses. There is greater latitude in how, when, and the degree to which faculty must modify and/or update their lectures in a more traditional face-to-face classroom setting than there is in an online environment.

\section{Specialists and Technology}

In today's world, when it comes to technology, nobody is an expert at everything. It used to be that there were few technologies to master relevant to teaching distance courses. For example, some early correspondence courses needed to deal with the technology of delivering and receiving assessments. There was generally one method, and everybody quickly mastered the method. But today, delivering asynchronous courses involves much more technology than in years past.

Good courses involve more than just uploading a few PowerPoint presentations and having students "read along." Many courses now include more interactive elements, such as simulations. Other courses involve providing complimentary lectures to the PowerPoint slides. Still others require students to interact in a blog-type of environment. In most of these cases, there is a technological need.

This need for access to specialists is not always readily available, nor does it come cheaply. Some institutions provide a full compliment of support staff; others have more limited resources. In either case, faculty face the need for specialists in developing, maintaining and updating courses that are often lacking in many institutions. In the current case, getting through the initial investment tended to be the most modest commitment. The greater commitment, and often unmet, is in maintaining and upgrading the course over time.

The examples of this technological / specialist need involved two courses. In one course, there was a simulation predicting political coups. In the second course, there was high-quality audio overlay for PowerPoint presentations that involved renting time in the University's performing arts center's sound booth. Both courses needed technological specialists such as computer programmers and sound engineers. This is pricey and introduces the possibility of inconsistency over time since the specialist may change.

In terms of specialists and technology, there is the problem of technological consistency. It is most desirable for the course to be consistent in terms of its technology use. Technological consistency means being consistent across courses and consistent within a given course over time. Given the relatively haphazard model of online course development early on, and the belief that each discipline would need completely different portals, interfaces, presentation styles, etc., there was little technological consistency across courses in the early stage of development. There were no less than 3 course developers working on five courses, resulting in 5 different course styles and formats. This was widely viewed as an institutional or organizational issue.

What proved to be more cumbersome from an individual faculty member's perspective was the lack of technological consistency over time in each individual course. In some cases, much of the technical work was done by graduate students. The resulting products were a series of .flash files that students could scroll through at their own leisure. When it was necessary to update one portion of the course, the graduate student who created the material was no longer at the University. None of the current students or technical support staff was able to re-create the same file format and style.

The faculty member was thus faced with two non-appealing selections. Choice one, the faculty member could produce those two files in a different format, thus taking away from the parsimony and seamlessness of the design. Choice two, the faculty member could reproduce all of the class presentations. The former option was chosen for the first revision. After several years, the course presentations represented a hodgepodge of presentation styles including PowerPoint presentations that could be navigated via flash file, PowerPoint presentations that had audio overlaid, and a PowerPoint presentation that was 
basically a live-recording of a simulated lecture. There was a loss of institutional memory and since there was no consistent strategy for course development and creation the course quality quickly degraded. The course was overhauled during a later revision but it is unclear whether this will lead to a consistent, long term product.

Faculty members must take into consideration the type and consistency of technical support and the degree to which there will be institutional memory. Better yet, the institution should develop a basic framework under which all faculty members must deliver their courses. Not only a consistent branding interface or portal, but a consistent method of content delivery.

The faculty member must also carefully consider the role technology plays in not only course development, but course delivery. It has quickly become fairly standard practice for online courses to use some combination of Facebook, Twitter, Podcasts and Blogs to facilitate communicate between instructors and students and between students themselves. One implication of using this approach may be the students' expectations that the course follows a model closer to the 24/7 approach than a more traditional schedule. One student even complained about a faculty member not promptly responding to an email inquiry made on Saturday that was not responded to by Sunday evening! Twitter itself may be an issue given the spontaneous nature of the communication and its instant accessibility. There has been more than one widely publicized account of public figures getting in trouble using Twitter; there are also several documented accounts of students and teachers getting in trouble using Facebook and Twitter. The university should have a policy that deals with the use of certain technologies, such as Facebook and Twitter, to provide faculty members with a greater sense of comfort regarding the boundaries of technology use.

\section{The Human Touch}

While not tied to the institutional environment per se, there is a concern about faculty losing the "human touch" when it comes to online teaching and learning; face-to-face interactions that often comprise good teaching are lost. For example, the instructor is not able to scan the classroom to "read" faces or body language to see whether students understand the topic. Instructors are left to other mechanisms such as message boards, email, or blog postings to determine whether students "get it". Alternatively, instructors can resort to a series of small assignments or quizzes meant to tap understanding, but it is still a weak proxy for the interaction that occurs in the classroom.

An instructor can help mimic the "human touch" by including audio as part of the course presentation and posting student profiles. In the case presented here, there were numerous strategies built into different courses to address the concern. First, lectures were recorded and overlaid to PowerPoint slides so the students could 'hear' the instructor.
Second, an instructor used podcasts to field specific questions; students would post messages on a blog and the instructor would use technology to broadcast actual verbal responses. Third, an instructor would regularly monitor the blog / message board and update the questions / answers in a fairly quick manner; this allowed him to see whether the students 'got it' by their responses to the questions he posted on the blog. Fourth, an instructor held real-time, synchronous office hours to be more engaged with his students. These are but a few examples; there were a host of methods individual faculty implemented to try and stay in closer touch with their students.

This relates to the institution's cultural, political or organizational culture in that there may be established protocols that must be followed. For example, a university may either encourage or prohibit the use of Tweeting or Facebook. As for the example used throughout this manuscript, a senior faculty member later began to use podcasts to reach his students and make his class more personal in a face-to-face setting. This was so successful that a seminar was offered to encourage faculty to use podcasts in their classes, both face-to-face and online. The use of technology as a form of communication is vital for online classes and there is a range of choices. The institution's role affects the development and delivery of online courses either through active involvement and intervention or through passive acceptance. The instructor's own comfort level and competence may also prove to be critical factors.

\section{Conclusions}

Faculty members operate in an organizational environment that affects their behavior and choices in numerous, seemingly innocuous ways. They are key players in the burgeoning development of online courses. They are often offered "incentives" in the form of cash stipends, reduced teaching loads, and other benefits to develop online courses. They are often not told of the many hidden costs associated with developing these courses: loss of research productivity, possibly lower merit raises, commitment to future offerings, time invested in maintaining and improving the course, lack of institutional support, and technological limitations or complications. They are often unaware of the role of a university's commitment to teaching technology and excellence and how this affects online course development and delivery.

Faculty members are similarly unaware of the potential concerns regarding the political environment associated with online teaching. There are often competing political agendas, competing interests in ownership and a broader political environment in action. In this particular case, there were three distinct administrative units providing financial support for course development - all with different interests. The faculty members needed to negotiate their way through the thickets to satisfy, to some extent, the Provost, the Associate Vice-Provost and the Dean of the College of 
Continuing Studies.

There was also an unexpected reaction from some faculty members and administrators that were opposed to full-scale online course development. When it was colleagues, there was tension, but when it was the administration the concern was greater. In at least two cases, faculty members developed online courses that were caught in the cross-fire; the faculty member invested hundreds of hours in instructional design and online course development for the course to be taught once. Any subsequent offerings were blocked by Department Heads. In this case, the cost of developing the online course was substantial and unexpected.

Finally, there are issues of the needed resources for continually maintaining and revising the course. As more courses are developed there is a cumulative demand on resources; it takes a certain amount of personnel to develop new online courses and to maintain online courses - this demand grows over time. This means that there either is a continued expansion of support personnel and technical specialists or the faculty members of already designed courses must take on a growing share of the technical work to maintain their courses. This is yet another constraint on subsequent course development since the course becomes so much work that the faculty member is reluctant to develop future courses. This has occurred in at least two cases in the current study.

What does all of this mean? There is a general organizational, socio-cultural and political environment that has the potential to serve as a facilitating mechanism for online course development and delivery. Unfortunately, in this study, that is not the case. As these factors become more widely known, there may be a reduction effect on future online course development. To avoid this potential slow-down, colleges and universities must take action to remedy the various limitations and concerns facing faculty members that might influence online course development and delivery. Similarly, faculty members need to be made aware of the quagmire that they must navigate in order to successfully develop and deliver online courses, both initially and over time.

\section{REFERENCES}

[1] Berg, Gary. 2002. Why Distance Learning? High Education Administrative Practices. Praeger Press, Westport: CT.

[2] Chao, Tracy, Tami Saj, and Felicity Tessier. 2006. "Establishing a Quality Review for Online Courses." EDUCASE Quarterly 29(3): 32-39.

[3] Dutton, John and Marilyn Dutton. 2005. "Characteristics and Performance of Students in an Online Section of Business Statistics." Journal of Statistics Education 13(3). www.amstat.org/publications/jse/v13n3/dutton.html

[4] Dutton, John, Marilyn Dutton, and Jo Perry. 2002. "How Do
Online Students Differ from Lecture Students?" Journal of Asynchronous Learning Networks 6(1). http://www.aln.org/ publications/jaln/v6n1/v6n1_dutton.asp

[5] Fjermestad, Jerry, Starr Hiltz, and Yi Zhang. 2004. "Effectiveness for Students: Comparisons of "In-Seat" and ALN Courses." Pp. 39-81 in Learning Together Online: Research on Asynchronous Learning Networks, edited by Starr Hiltz and Ricki Goldman. Mahwah, NJ: Erlbaum Publishers.

[6] Horton, Sarah. 2000. Web Teaching Guide: A Practical Approach to Creating Course Web Sites. Yale University Press. New Haven: CT.

[7] Knowles, Evelyn and Kathleen Kalata. 2007. "A Model for Enhancing Online Course Development." Innovate: Journal of Online Education 4(2) http://www.innovateonline.info/ind ex.php?view=article $\&$ id $=456$

[8] Ko, Susan and Steve Rossen. 2003. Teaching Online: A Practical Guide. Houghton Mifflin Company. New York: NY.

[9] Koontz, Franklin, Li Hongqin and Daniel Compora. 2006. Designing Effective Online Instruction: A Handbook for Web-Based Courses. Rowan and Littlefield Education. Lanham, MD.

[10] Kranch, Douglas. 2008. "Who Owns Online Course Intellectual Property." The Quarterly Review of Distance Education 9(4): 349-356.

[11] Loggie, Kathryn Ann, Ann Barron, Elizabeth Gulitz, Tina Hohlfield, Jeffrey Kromrey and Phyllis Sweeney. 2007. "Intellectual Property and Online Courses." The Quarterly Review of Distance Education 8(2): 109-125.

[12] Oblinger, Diana and Brian Hawkins. 2006. "The Myth of Online Course Development: "A Faculty Member Can Individually Develop and Deliver an Effective Online Course." EDUCASE Review 41(1): 14-15.

[13] Porter, Lynnette. 2010. Developing an Online Educational Curriculum: Technologies and Techniques. Information Science Publishing, Hershey, PA

[14] Powell, Gary. 2001. "The ABCs of Online Course Design." Educational Technology 41(4): 43-47.

[15] Russell, Thomas. 2001. The No-Significant-Difference Phenomenon: A Comparative Research Annotated Bibliography on Technology for Distance Education. The International Distance Education Certification Center. Montgomery, AL.

[16] Schultz, Marian, James Schultz, and Gene Round. 2008. "Management of Academic Quality: A Comparison of Online Versus Lecture Course Outcomes." Journal of College Teaching and Learning 5(10): 23-28.

[17] Smith, Robin. 2008. Conquering the Content: A Step-by-Step Guide to Online Course Design. John Wiley \& Sons. San Francisco, CA.

[18] Sussman, Stephen and Lee Dutter. 2010. "Comparing Student Learning Outcomes in Face-to-Face and Online Course Delivery." Online Journal of Distance Learning Administration 13(4).

http://www.westga.edu/ distance/ojdla/winter134/sussman dutter134.html 
[19] Urtel, Mark. 2008. "Assessing Academic Performance Between Traditional and Distance Education Course Formats." Educational Technology \& Society 11(1): 322-330.
[20] Vai, Marjorie and Kristen Sosulski. 2011. Essentials of Online Course Design: A Standards Based Guide. Taylor \& Francis. New York: NY 